\title{
Hybrid histories
}

\author{
Citation for published version (APA):
}

van der Heijden, T. (2018). Hybrid histories: technologies of memory and the cultural dynamics of home movies, 1895-2005. [Doctoral Thesis, Maastricht University]. Maastricht University. https://doi.org/10.26481/dis.20180118tvdh

Document status and date:

Published: 01/01/2018

DOI:

10.26481/dis.20180118tvdh

Document Version:

Publisher's PDF, also known as Version of record

\section{Please check the document version of this publication:}

- A submitted manuscript is the version of the article upon submission and before peer-review. There can be important differences between the submitted version and the official published version of record.

People interested in the research are advised to contact the author for the final version of the publication, or visit the DOI to the publisher's website.

- The final author version and the galley proof are versions of the publication after peer review.

- The final published version features the final layout of the paper including the volume, issue and page numbers.

Link to publication

\footnotetext{
General rights rights.

- You may freely distribute the URL identifying the publication in the public portal. please follow below link for the End User Agreement:

www.umlib.nl/taverne-license

Take down policy

If you believe that this document breaches copyright please contact us at:

repository@maastrichtuniversity.nl

providing details and we will investigate your claim.
}

Copyright and moral rights for the publications made accessible in the public portal are retained by the authors and/or other copyright owners and it is a condition of accessing publications that users recognise and abide by the legal requirements associated with these

- Users may download and print one copy of any publication from the public portal for the purpose of private study or research.

- You may not further distribute the material or use it for any profit-making activity or commercial gain

If the publication is distributed under the terms of Article $25 \mathrm{fa}$ of the Dutch Copyright Act, indicated by the "Taverne" license above, 


\section{Samenvatting}

Dit proefschrift bestudeert hoe verschillende generaties in de afgelopen eeuw hun familieherinneringen hebben vastgelegd met behulp van film, video en digitale mediatechnologieën. In het bijzonder wordt belicht hoe veranderingen in deze "geheugentechnologieën" nieuwe vormen van maken en vertonen teweeg hebben gebracht in de familiefilm als twintigste-eeuwse herinneringspraktijk. Hoewel het tegenwoordig heel vanzelfsprekend is om het dagelijkse (familie) leven vast te leggen met behulp van een smartphone of digitale camera en deze beelden direct te delen met anderen, was het maken en vertonen van familiefilms en -video's tot voor kort een relatief exclusieve praktijk. Na de uitvinding van de filmcamera aan het eind van de negentiende eeuw raakte een kleine groep van welgestelde hobbyisten gefascineerd door het technische wonder van het bewegend beeld. Het amateurfilmen werd al toegankelijker met de komst van diverse smalfilmtechnologieën in de jaren twintig en dertig van de twintigste eeuw. Een populair huiselijk ritueel ontwikkelde zich pas echt vanaf de jaren zestig, vooral na de komst van de gebruiksvriendelijke Super 8 filmcamera. De intrede van de videocamera eind jaren zeventig en tachtig bracht niet alleen een langere opnameduur en de mogelijkheid om beeld en geluid synchroon op te nemen, maar veranderde ook de context waarin familiefilms werden vertoond. Waar men voorheen een filmprojector gebruikte, werd in het videotijdperk de camera direct aangesloten op de televisie. Begin $2 \mathrm{r}^{\mathrm{e}}$ eeuw beperkt het vastleggen en vertonen van familiefilms zich niet langer tot de huiskamer, maar worden de vastgelegde herinneringen met de hele wereld gedeeld dankzij digitale opnametechnologieën en sociale-mediaplatformen.

Dit proefschrift analyseert deze historische transformaties in het maken en vertonen van familiefilms vanuit een langetermijnperspectief. De focus ligt op de periode tussen 1895 , het jaar waarin de gebroeders Lumière hun eerste familiefilm projecteerden, en 2005 , het jaar waarin YouTube werd gelanceerd als sociaalmediaplatform. Aan de hand van een historische discoursanalyse van Nederlandse amateur foto-, film- en videotijdschriften wordt de wisselende relatie tussen geheugentechnologieën en -praktijken systematisch onderzocht. Daarbij worden vier belangrijke transitieperioden onderscheiden in de culturele dynamiek van de familiefilm. Iedere transitieperiode geeft inzicht in veranderingen in gebruikerspraktijken die samenhangen met de komst van een nieuwe geheugentechnologie, namelijk: 
(1) De komst van 9,5 $\mathrm{mm}, 16 \mathrm{~mm}$ en $8 \mathrm{~mm}$ smalfilmtechnologieën in de jaren twintig en dertig

(2) De komst van Super 8 en Single 8 cassettefilmtechnologieën in de jaren zestig

(3) De komst van home videotechnologieën in de jaren zeventig en tachtig

(4) De komst van digitale mediatechnologieën in de jaren negentig en 2000

Ieder empirisch hoofdstuk bespreekt één van deze transitieperioden op basis van twee complementaire analytische concepten: dispositief en gebruikersgeneraties. Het dispositief-concept komt oorspronkelijk uit de filmwetenschap en biedt een raamwerk om de relaties tussen de technologie, inhoud en perceptie van een medium te bestuderen. In de geschiedenis van de familiefilm als twintigsteeeuwse herinneringspraktijk kunnen verschillende dispositieven worden onderscheiden. Zo kenmerken "smalfilm-dispositieven" zich door het gebruik van $9,5 \mathrm{~mm}, 16 \mathrm{~mm}$ en $8 \mathrm{~mm}$ smalfilmcamera's en projectoren (technologie), overwegend statisch, geluidloos en zwart-wit- of kleur-filmbeeld (inhoud) en huiselijke filmprojectie op groot doek (perceptie). "Home video-dispositieven" kenmerken zich daarentegen tot het gebruik van home videosystemen als VHS en Betamax (technologie), het synchroon opnemen en afspelen van beeld en geluid, de lange opnameduur (inhoud) en het direct vertonen van de video-opnamen op de televisie-set (perceptie). Het zogeheten "familiefilm-dispositief" laat zich zodoende door de twintigste eeuw heen historiseren als een specifieke constellatie van technologie, inhoud en perceptie die telkens verandert (diachroon perspectief). Het concept van gebruikersgeneraties maakt het daarbij mogelijk om de dynamiek tussen verschillende gebruikers en gebruikersgroepen te analyseren zoals deze binnen specifieke transitieperioden gestalte krijgt door de komst van het nieuwe medium en dispositief (synchroon perspectief). Het benaderen van generaties op basis van technologiegebruik in plaats van op basis van leeftijd-cohorten maakt inzichtelijk hoe verschillende typen gebruikers zich (her)positioneren ten opzichte van de nieuwe amateur-en geheugentechnologie en de daarmee samenhangende praktijken en discoursen. Zo bracht de komst van de eerste home videosystemen in de late jaren zeventig en tachtig bijvoorbeeld een sterke dynamiek teweeg tussen videogebruikers die geen filmervaring hadden ("beginnende gebruikers") en ervaren filmers die nieuwsgierig waren naar de nieuwe mogelijkheden van het videomedium ("meegaande gebruikers") of juist vasthielden aan hun vertrouwde medium ("volhardende gebruikers"). Door het gebruik van dispositief en gebruikersgeneraties als analytische concepten en de focus op concrete transities in de familiefilm als twintigste-eeuwse herinneringspraktijk worden de materialiteit van film, video en digitale media als geheugentechnologieën, de sociale context waarin deze worden gebruikt, en de gebruikersdynamiek en betekenissen die zij genereren op systematische wijze, in hun wederzijdse interacties, geanalyseerd. 
Hoofdstuk 2, het eerste van de vier empirische hoofdstukken van dit proefschrift, belicht de vroege periode van de familiefilm, waarin deze als gebruikerspraktijk nog sterk is verbonden met de (amateur)fotografie. Aan het begin van de twintigste eeuw werd het amateurfilmen vaak nog beschouwd als een tak van de fotografie, genaamd "kinematografie". De eerste bewegend beeld-hobbyisten maakten gebruik van allerlei fotografische technieken en conventies, vooral in filmopname- en ontwikkelpraktijken, terwijl bij huiselijke vertoningspraktijken juist de projectiepraktijken van de toverlantaarn en vroege cinema een referentiekader boden. De eerste gebruikers van de amateurfilm-camera waren veelal mannelijke hobbyisten, die nieuwsgierig waren naar de technische mogelijkheden om "levende beelden" op te nemen en te vertonen. Het vastleggen van betekenisvolle momenten uit het familieleven op bewegend beeld maakte het amateurfilmen van begin af aan een aantrekkelijke herinneringspraktijk, zoals de familiefilms Le Repas de Bébé van Louis Lumière uit 1895 en De Wigwam van Joris Ivens uit 1912 illustreren. De komst van de Pathé 9,5 $\mathrm{mm}$, Kodak $16 \mathrm{~mm}$ en $8 \mathrm{~mm}$ smalfilmformaten en daarbij behorende opname- en vertoningssystemen leidden uiteindelijk tot de standaardisatie van amateurfilmtechnologieën. Dit droeg bij aan een verdere differentiatie tussen professionals en amateurs, zowel in de gebruikerspraktijk als het daarmee samenhangende discours. Met de komst van allerlei amateurfilmwedstrijden, de oprichting van de Nederlandsche Smalfilmliga als nationale amateurfilmclub en de lancering van het eerste Nederlandse amateurfilmtijdschrift ("Het Veerwerk") institutionaliseerde de amateurfilmpraktijk aan het begin van de jaren dertig. Nieuwe "filmische technieken", waaronder het maken van filmscenario's, titels en montage, werden bevorderd door aan deze amateurfilminstituten verbonden actoren. Het maken en vertonen van films ontwikkelde zich in deze periode zodoende geleidelijk tot een zelfstandige praktijk, die steeds meer werd beoefend door zowel serieuze hobbyisten als familiefilmers.

Hoofdstuk 3 bespreekt de sterke popularisering van de familiefilm als herinneringspraktijk in de naoorlogse periode, met een focus op de late jaren vijftig en zestig. Onder invloed van uiteenlopende factoren, zoals de toename van welvaart, vrije tijd en de veranderende status van de familie in de samenleving, ontwikkelde het maken en vertonen van familiefilms zich van een technische hobby en relatief exclusieve gebruikerspraktijk tot een populaire vorm van tijdbesteding voor welgestelde families. De komst van het gebruiksvriendelijke Super 8-cassettefilmsystem midden jaren zestig droeg bij aan de verdere toegankelijkheid en verspreiding van amateurfilmtechnologieën. De industrie promootte en benadrukte in deze periode het gebruiksgemak van moderne, geminiaturiseerde en semi-geautomatiseerde amateurfilmcamera's en -projectoren. Niet in de laatste plaats om het vastleggen van familieherinneringen als huiselijke praktijk te bevorderen onder nieuwe gebruikersgroepen, waaronder (huis)vrouwen. Waar het amateurfilmen voorheen een overwegend mannelijke en technische aangelegenheid betrof voor leden van 
de welgestelde klasse, droeg de overgang van smalfilm naar cassettefilm bij aan een democratisering van de gebruikerspraktijk. Naast de discursieve constructie van vrouwen als "nieuwe gebruikers" van de amateurfilmcamera veranderden in deze periode ook de uiterlijke kenmerken van de familiefilm. Men filmde steeds meer in kleur in plaats van zwart-wit en de filmbeelden werden steeds vaker van een geluidslaag voorzien. Het maken van geluidsfilms door amateurs werd bevorderd door de komst van magnetische bandopnametechnologieën en synchronisatietechnieken. Het veranderende medialandschap bood echter niet alleen nieuwe mogelijkheden voor amateurfilmers, maar compliceerde ook de gebruikerspraktijk. De komst van televisie als modern huiselijk medium leidde bijvoorbeeld tot een sterk contrast met de traditionele filmische projectiepraktijk en -beleving op het grote doek. Een verandering die zich nog intenser zou doen voelen met de komst van home video als nieuwe geheugentechnologie en drager van familieherinneringen.

Hoofdstuk 4 belicht hoe het veranderende medialandschap en de komst van home videotechnologieën in het bijzonder leidden tot een sterke hybridisering van familiefilmpraktijken in de jaren zeventig en tachtig. Aan de hand van drie fasen in de ontwikkeling van video als opnametechnologie en huiselijk medium - van de eerste consumenten-videosystemen uit de jaren zestig, bedoeld voor het opnemen van televisieprogramma's, via de komst van diverse concurrerende videosystemen (Betamax, VHS, Video20oo) eind jaren zeventig en begin jaren tachtig, tot aan de komst van de camcorder en verschillende hoge kwaliteit videosystemen eind jaren tachtig en begin jaren negentig - laat dit hoofdstuk zien hoe video als medium altijd intrinsiek verbonden is geweest met andere mediatechnologieën, waaronder televisie, de bandrecorder, film en later de computer. Video's materiële, praktische en discursieve intermedialiteit leidde tot hybride gebruikerspraktijken, zoals "tele-recording" (het opnemen van televisieprogramma's met een filmcamera) en diverse hybride vertoningsapparaten die de huiselijke "projectie" van films op de televisie mogelijk maakten. De verschillende consumentenvideosystemen gingen de strijd aan met filmische geheugentechnologieën, zowel in de amateurfilmclubs als in de huiselijke sfeer. De lange opnameduur, de mogelijkheid om beeld en geluid synchroon op te nemen en direct na opname te bekijken of te wissen, maakten video een aantrekkelijk medium voor specifieke gebruikersgroepen. Tegelijkertijd bracht de komst van video grote veranderingen of zelfs beperkingen in bestaande gebruikerspraktijken. De mogelijkheid om video-opnamen direct te wissen of weer te geven op het televisiescherm leidde bijvoorbeeld tot een andere gebruikersdynamiek in de vertoningscontext. De esthetiek van video, als elektromagnetisch medium, verschilde van die van film. De effecten van video op de amateurfilmpraktijk waren wellicht het grootst op montagegebied, waar de plakpers vervangen werd door elektronische beeldbewerking, wat een andere vorm van amateurisme en vakmanschap vereiste. De grote verschillen 
in gebruikerspraktijken tussen film en video zorgden ervoor dat video tegenover film lang als secundair of hooguit complementair werd beschouwd, vooral door ervaren (amateur)filmers. Slechts zeer geleidelijk werd video als zelfstandig amateurmedium en geheugentechnologie geaccepteerd.

Hoofdstuk 5, het laatste empirische hoofdstuk, bespreekt hoe de overgang van home video naar digitale mediatechnologieën leidde tot een multimediatisering van de familiefilm als herinneringspraktijk. De opkomst van de personal computer, digitale camcorders en smartphones bracht een verandering teweeg in de manier waarop men (familie)herinneringen kon vastleggen, delen en bewaren. De focus op de jaren negentig en 2000 maakt het mogelijk enkele belangrijke ontwikkelingen voorafgaand aan de komst van sociale media als YouTube, Facebook en andere online videoplatformen uit te lichten. Een belangrijke ontwikkeling was bijvoorbeeld technologische convergentie. De popularisering van de personal computer, een schoolvoorbeeld van een geconvergeerde mediatechnologie, liep vrijwel gelijk met de lancering van de eerste digitale camcorders. De overgang van de magnetische band en optische schijf naar de memory chip als efficiënte drager van bits and bytes stimuleerde de verregaande miniaturisering en convergentie van digitale opnametechnologieën. Digitale camcorders brachten bijvoorbeeld foto- en videofunctionaliteiten samen. De komst van nieuwe features, zoals beeldstabilisatie-sensoren en het roteerbare LCD scherm, brachten de fotografie terug in het discours rondom de opnamepraktijk, vergelijkbaar met de beginperiode van het thuisfilmen. Een andere belangrijke ontwikkeling in de jaren negentig is de komst van het World Wide Web en de zogeheten deelculturen (sharing cultures), die uiteindelijk de grenzen tussen het private en het publieke zouden doen verschuiven. De overgang van analoge naar digitale media leidde tot een veelvoud aan schermen, waarbij het computerscherm, televisiescherm en de schermen van laptops, tablets en smartphones naast elkaar worden gebruikt. De veelvoud aan schermen en daarmee samenvallende veranderingen in beeldresolutie en -formaat gaven nieuwe mogelijkheden in de vertoningspraktijk, bijvoorbeeld in het simultaan opnemen en vertonen van bewegend beeld en geluid. Tegelijkertijd ontstonden nieuwe uitdagingen en problemen, zoals digitale beeldvervorming en het zogeheten vertical video syndrome. Het hoofdstuk sluit af met een reflectie op het hergebruik van analoge mediatechnologieën zoals Super 8 film in het digitale tijdperk.

In hoofdstuk 6 keer ik terug naar de centrale vraagstelling van dit proefschrift, namelijk de vraag hoe film, video en digitale media als veranderende geheugentechnologieën de aanzet hebben gegeven tot nieuwe praktijken op het gebied van het maken en vertonen van familiefilms. Het langetermijnperspectief maakt het mogelijk enkele algemene conclusies te trekken. Hoewel families in de loop van tijd hun vakanties, verjaardagen en de eerste stapjes van hun kinderen zijn blijven opnemen en delen met hun omgeving, is het evident dat hedendaagse deelculturen 
fundamenteel verschillen van de filmische herinneringspraktijken aan het begin van de twintigste eeuw. Als dragers van familieherinneringen zijn celluloid films en magnetische videotapes grotendeels vervangen door digitale bits and bytes; handzame filmcamera's, projectoren, analoge videorecorders en camcorders raakten verouderd met de komst van digitale en mobiele opnametechnologieën. De kenmerken van familiefilms zijn veranderd van zwart-wit naar kleur, van stil naar geluid, en van enigszins stabiele archivale bronnen naar efemere data die worden opgeslagen in de cloud. Conform de hypothesen van het onderzoek is het maken en vertonen van familiefilms in de loop van de twintigste eeuw geleidelijk aan veranderd van een relatief technische en exclusieve praktijk naar een toegankelijke en bovendien sterk verjongde culturele praktijk, waarbij de gebruikerscontexten rond het maken en vertonen van familiefilms geleidelijk verschuiven van het private naar het publieke domein. Tegelijkertijd kunnen deze transformaties worden genuanceerd op basis van de empirische onderzoeksresultaten. De verschuiving van private naar publieke gebruikerscontexten wordt bijvoorbeeld vaak geassocieerd met de overgang van het analoge naar het digitale tijdperk, in het bijzonder met de komst van online gebruikersplatformen zoals YouTube. In de jaren twintig en dertig boden echter diverse amateurfilmclubs al de mogelijkheid aan amateurs om hun zelfgemaakte, vaak huiselijke beelden te vertonen aan een groot publiek.

De focus op specifieke transitieperioden maakt het niet alleen mogelijk om lange-termijn historische veranderingen te beschrijven en te duiden, maar maakt ook de vele ontwikkelingen binnen deze transformaties zichtbaar. Transities in mediatechnologieën en -praktijken laten zich niet altijd vatten in termen van continuïteit en discontinuïteit. Dit geldt zeker voor ontwikkelingen in zowel het video als het digitale tijdperk, waarin de korte levenscyclus en snelle opvolging van mediatechnologieën leidde tot een grotere onderlinge verbondenheid of zelfs coexistentie van mediatechnologieën en -praktijken. Eén van de centrale inzichten van dit proefschrift is dan ook dat de verschillende familiefilm-dispositieven smalfilm, Super 8, home video en digitale media - in toenemende mate met elkaar zijn verbonden of zelfs convergeren. Eveneens neemt de gebruikersdynamiek toe gedurende de twintigste eeuw, waardoor gebruikersgeneraties niet alleen korter worden maar elkaar ook steeds meer overlappen. De smalfilm gebruikersgeneratie kent de langste levensloop: meer dan zestig jaar. De Super 8 gebruikersgeneratie is daarmee vergeleken al van kortere duur. Home video en digitale gebruikersgeneraties krijgen te maken met een veelvoud aan technologische systemen en formats die zich steeds vernieuwen. Digitale gebruikersgeneraties hebben relatief de kortste levensloop, met slechts vijf tot tien jaar tussen de overgangen van magnetische band via optische schijf naar memory chip als digitale dragers. Op grond van de empirisch onderbouwde constatering dat de verschillende dispositieven en gebruikersgeneraties elkaar sneller opvolgen of zelfs in toenemende mate gaan 
overlappen, kan men vraagtekens plaatsen bij de bruikbaarheid van deze analytische concepten. Wanneer verschillende historische constellaties van technologie, inhoud en perceptie elkaar overlappen en daardoor historisch gezien minder sterk kunnen worden onderscheiden, neemt de waarde en bruikbaarheid van het dispositief-concept om diachrone relaties te analyseren af. Het potentieel van het gebruikersgeneraties-concept om de gebruikersdynamiek te analyseren implodeert zodra de versnelde toename van nieuwe geheugentechnologieën een veelvoud aan gebruikersgeneraties teweegbrengt binnen specifieke transitieperioden. Kortom, de versnelde technologische transformaties en de daaropvolgende toename van gebruikersdynamiek compliceert niet alleen de relatie tussen veranderende geheugentechnologieën en gebruikerspraktijken in de tijd, maar maakt de conceptuele middelen om deze veranderende relatie te bestuderen uiteindelijk minder effectief.

De vraag hoe we de toegenomen complexiteit in de dynamiek tussen veranderende geheugentechnologieën en gebruikerspraktijken op een meer procesmatige manier kunnen benaderen, staat centraal in het laatste gedeelte van het slothoofdstuk. Daartoe wordt verkend hoe de notie van hybriditeit een alternatief vertrekpunt kan vormen om transities in mediatechnologieën en -praktijken te begrijpen vanuit zowel een diachroon als synchroon perspectief. Op basis van de empirische en conceptuele onderzoeksresultaten kan namelijk worden geconcludeerd dat een langdurige historische en systematische studie van mediatransities - digitale mediatransities in het bijzonder - gebaat is bij een perspectief dat de toegenomen complexiteit in de dynamiek tussen veranderende geheugentechnologieën en gebruikerspraktijken onderkent. Het is mogelijk om drie vormen van hybriditeit te onderscheiden in de onderzochte transitieperioden van de geschiedenis van de familiefilm als twintigste-eeuwse herinneringspraktijk:

- Hybride technologieën: komen voor wanneer twee verschillende mediatechnologieën samenvallen. Voorbeelden hiervan zijn hybride vertoningsapparaten voor de "projectie" van films op het televisiescherm (vb. Polavision) en hybride montagetechnologieën voor zowel analoge als digitale montagepraktijken ( vb. Casablanca). Ook de Lumière Cinematograph uit de late negentiende eeuw kan als een hybride technologie worden gezien. Niet alleen omdat het een filmcamera, ontwikkelaar en projector in één apparaat verenigde, maar ook omdat het voor de filmprojectie gebruik maakt van het lichtmechanisme van de toverlantaarn.

- Hybride praktijken: komen voor wanneer gebruikers een nieuw medium hanteren met het oude medium als referentiekader. Een voorbeeld is de vroege filmpraktijk waarin conventies van de (amateur)fotografie sterk doorklinken, bijvoorbeeld in het poseren voor de camera. Een ander voorbeeld is de praktijk van "tele-recording": het opnemen van televisieprogramma's met de filmcamera in plaats van de videorecorder. 
- Hybride discoursen: komen voor wanneer een oude terminologie wordt gebruikt om een nieuwe technologie, diens gebruikers en/of gebruikerspraktijken te beschrijven. Een voorbeeld is de beschrijving van film in termen van "kinematografie", "levende beelden" en "bewegende foto's", of de beschrijving van video in termen van "electronische cinematografie" en "tape-recorder voor film".

Vanuit een langetermijnperspectief kan worden gesteld dat (1) hybriditeit zich verschillend kan manifesteren, zowel diachroon als synchroon; dat (2) hybriditeit is gebaseerd op intermedialiteit, dat wil zeggen de diachrone of synchrone relaties tussen verschillende mediatechnologieën; en (3) dat wat zich als hybride laat kwalificeren veranderlijk is door de tijd. Op basis van deze reflecties wordt een hybride benadering van mediageschiedschrijving voorgesteld die niet langer het verleden reconstrueert in termen van verandering en continuïteit, maar in plaats daarvan vertrekt vanuit de fundamentele intermedialiteit en veranderlijkheid van mediatechnologieën, -praktijken en -discoursen. Een dergelijke benadering beschouwt hybriditeit niet als uitzondering, maar als de enige constante factor in mediahistorische ontwikkeling. Een hybride mediahistorische benadering van de familiefilm als twintigste-eeuwse herinneringspraktijk reduceert haar geschiedenis zodoende niet tot louter dominante veranderingen van film via video naar digitale media als geheugentechnologieën, maar onderkent juist de complexiteit van mediatechnologieën, -praktijken en -discoursen in hun permanente staat van transitie. 